Int. J. Electrochem. Sci., 15 (2020) 10197 - 10211

International Journal of

ELECTROCHEMICAL

SCIENCE

www.electrochemsci.org

\title{
Anticorrosive Performance of Vinyl Butyral-co-vinyl alcohol-co- vinyl Acetate Based Copolymer Adsorbed on Steel Surfaces. Electrochemical and AFM Studies
}

\author{
Claudia Merişanu ${ }^{1,2}$, Adriana Samide ${ }^{1, *}$, Gabriela Eugenia Iacobescu ${ }^{3, *}$, Bogdan Tutunaru ${ }^{1}$, \\ Cristian Tigae ${ }^{1}$, Alexandru Popescu ${ }^{2}$
}

${ }^{1}$ University of Craiova, Faculty of Sciences, Department of Chemistry, 107i Calea Bucuresti, Craiova, Romania

${ }^{2}$ University of Craiova, Faculty of Sciences, Doctoral School of Sciences, A.I. Cuza no.13, Craiova, Romania

${ }^{3}$ University of Craiova, Faculty of Sciences, Department of Physics, A.I. Cuza no.13, Craiova,

Romania

*E-mail: samide_adriana@yahoo.com; gabrielaiacobescu@yahoo.com

doi: $10.20964 / 2020.10 .25$

Received: 6 May 2020 / Accepted: 14 July 2020 / Published: 31 August 2020

The copolymer film anticorrosive performance based on poly(vinyl butyral-co-vinyl alcohol-co-vinyl acetate), called in this study as PVBA, deposited by the dipping method on the carbon steel and 304L stainless steel surfaces from methanolic solution was studied by open circuit potential (OCP) measurements, potentiodynamic polarization and electrochemical impedance spectroscopy (EIS). The morphological characteristics of the uncovered and covered surfaces with copolymer film, before and after corrosion were identified by atomic force microscopy (AFM). The average protection performance (P\%) of PVBA adsorbed on metallic surfaces corroded in $0.9 \% \mathrm{NaCl}$ solution reached the value of $64 \pm$ $2 \%$ for carbon steel and $72 \pm 2 \%$, respectively, for 304L stainless steel. AFM 3D images, before corrosion, display coherently organized coatings adsorbed on the surfaces of steels, with a network characteristic, more obviously in the case of 304L stainless steel than that of carbon steel. After corrosion, AFM shows that the surface upper-layers preserve their features, suggesting that the coating remains anchored to the metal surface for a long time, but the polymer swelling in $\mathrm{NaCl}$ solution causes the relative detachment of the film from the substrate, with the formation of some free areas on which the oxidation processes can be accelerated, leading to PVBA anticorrosive performance disturbance.

Keywords: PVBA copolymer; Carbon steel and 304L Stainless steel; Anticorrosive coating; Electrochemical measurements; Atomic force microscopy (AFM)

$\underline{\text { FULL TEXT }}$ 
(C) 2020 The Authors. Published by ESG (www.electrochemsci.org). This article is an open access article distributed under the terms and conditions of the Creative Commons Attribution license (http://creativecommons.org/licenses/by/4.0/). 